\title{
Numerical modeling of underwater noise induced by shipping traffic in the Balearic Sea
}

\author{
$1^{\text {st }}$ Tiago C. A. Oliveira \\ Physics Department \\ \& Centre of Environmental \\ and Marine Studies \\ University of Aveiro \\ Aveiro, Portugal \\ toliveira@ua.pt
}

\author{
$2^{\text {nd }}$ Jordi Fonollosa \\ Department of Automatic Control \\ ESAII \& Barcelona School of \\ of Nautical Studies \\ UPC-BarcelonaTech \\ Barcelona \\ jordi.fonollosa.m@upc.edu
}

\author{
$3^{\text {rd }}$ Anna Mujal \\ Department of Nautical Studies and \\ Engineering \& Barcelona School \\ of Nautical Studies \\ UPC-BarcelonaTech \\ Barcelona \\ anna.mujal@upc.edu
}

\begin{abstract}
We present a novel methodology to model the underwater noise induced by ship traffic in the Balearic Sea. In this regard, a three-dimensional underwater sound propagation model is used with realistic time-dependent physical oceanographic inputs (wind waves, temperature, and salinity) and ship information (location, velocity and ship type) from an Automatic Identification System (AIS).

Index Terms-Shipping noise, AIS
\end{abstract}

\section{INTRODUCTION}

Human activities in the ocean have increasingly added artificial sounds to this environment. Recent research has shown that underwater noise induced by human activities, such as seismic airguns, ships, sonars, explosives or pile drivers, have the potential to impact marine ecosystems. More specifically, very loud noise of relatively short exposure can harm marine mammals, fish, marine invertebrates and zooplankton [1][6]. Consequently, the European Commission recommends the Member States the combined use of measurements and underwater sound models to ascertain levels and trends of underwater noise in the oceans and coastal areas. [7]

During the past decades, several models for the source level radiated by ships have been proposed [8]-[12]. More recently, underwater acoustic propagation models have been used to obtain ship noise maps [13]-[15].

In the ocean, acoustic propagation is affected by changes in water sound speed [16] induced by water temperature and salinity variability. Moreover, a variety of geological and physical oceanographic features can induce 3D effects (such as horizontal refraction, reflection, and diffraction) on sound propagation at different scales [17], [18].

The Balearic Sea is located in the northern part of the busy western Mediterranean pathway [19], which connects ships from the Gibraltar Strait to the south of Europe. This sea covers the area from the Balearic Islands to Catalonia (see Figure 1) and it is known for containing an important ecological diversity. [20], [21]

In this work we focus on modeling the underwater noise induced by the regular ferry lines (red and orange lines in Figure
2) connecting Barcelona to Balearic Island, emphasizing the route from Barcelona to Alcudia in Mallorca Island (orange lines in Figure 2). Based on this particular case, we study Transmission Loss (TL) variability due to daily and seasonal changes on water temperature and salinity in different parts of the Balearic Sea. The results presented here aim to contribute in creating a shipping noise forecast system to the Balearic Sea.

This paper is organized in five sections. In section 2 we introduce the methodology. In section 3 and 4 we present and discuss the results. Finally, concluding remarks are given in section 5 .

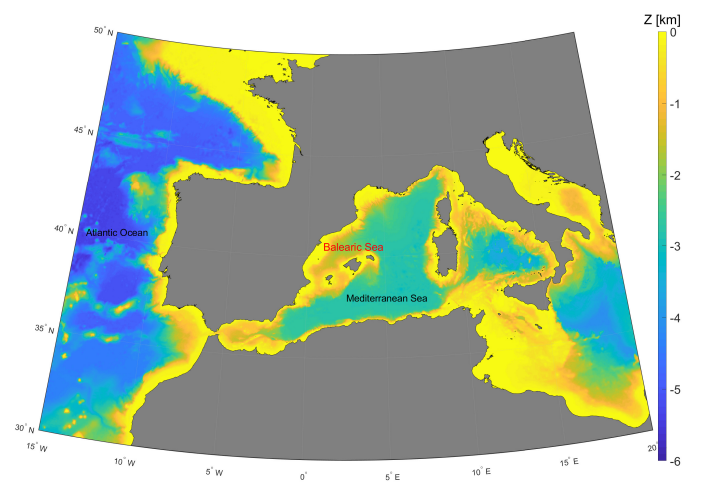

Fig. 1. Location of Balearic Sea

\section{Methodology}

\section{A. AIS}

The Barcelona School of Nautical Studies $\left(41.38^{\circ} \mathrm{N}\right.$, $2.18^{\circ} \mathrm{E}$ ) hosts an Automatic Identification System (AIS) receiver (SeaTraceR AIS Class B Transponder S.287) covering an area ranging from Barcelona to the Balearic Islands (approximately 120 nautical miles, see Figure 2). AIS is an information transmitter mandatory for vessels with gross tonnage larger than 300 GT since 2003 in the International Convention for the Safety of Life at Sea (SOLAS Agreement). However, 
recreational boats such as sailboats and sailing yachts have been recently including AIS system to their navigation aids. The main purpose of AIS systems is to assist on safety for the navigation and, in particular, to avoid collisions between vessels on cruise and maneuvering status.

AIS uses VHF channels to transmit dynamic (e.g. lat-lon position, velocity, heading) and static (e.g. vessel dimensions, the port of arrival) data. It can contain a total of 27 messages depending on the information. Some of these messages are automatically broadcasted to both inland and mobile stations. In particular, the messages used to evaluate shipping noise are Message 1-2-3 and 5 and Messages 18 and 24B. The former are originated by Class A AIS transmitters and have more detailed information, both static and dynamic, whereas the latter are from Class B transmitters, used mostly by recreational and smaller vessels.

\section{B. Physical oceanography}

Environmental parameters used in the acoustic model are obtained from the Copernicus Marine Environment Monitoring Service (CMEMS) analysis and forecast product MEDSEA ANALYSIS FORECAST PHY-006-013 (MEDSEA) [22]. This product uses the Nucleous for European Modelling of the Ocean (NEMO v3.6) [23] model to provide hourly mean fields of water temperature and salinity, with a horizontal resolution of approximately $4.63 \mathrm{~km}$ and for 141 vertical levels.

\section{Underwater acoustic modeling}

Dynamic data from the AIS system is used as a sound source definition in a three-dimensional Normal Mode model (Kraken 3D) [24]. This model is a combined package of Kraken [25], which solves the normal modes, and Field3D [26], which computes the acoustic field as a function of range and depth. The numerical simulations were run on a $3.0 \mathrm{GHz}$ Intel Core i7 (i7-9700) 8C CPU.

The bathymetric model needed in acoustic simulations is constructed using the $1 / 60^{\circ}$ resolution database ETOPO1 Global Relief Model (www.ngdc.noaa.gov/mgg/global/global.html) from the National Geophysical Data Center (NGDC). Sound speed model is calculated based on water salinity and temperature [27] provided by MEDSEA.

The geoacustic properties of the bottom are kept constant over range considering sound speed $c_{b}=1800 \mathrm{~m} / \mathrm{s}$, density $\rho=1500 \mathrm{~kg} / \mathrm{m}^{3}$ and attenuation $\beta_{b}=0.1 \mathrm{~dB} / \lambda$. Water density is considered to be constant with $\rho_{w}=1000 \mathrm{~kg} / \mathrm{m}^{3}$.

The simulation of difference frequencies requires different numerical discretization in models based on Normal Mode theory. As the wavelength decreases with increasing frequency, smaller space distances between calculation points must be used. As a rule of thumb, to solve the normal mode equation accurately in KRAKEN, a minimum of 10 points per wavelength should be considered in the water column. In Kraken 3D, Nprofy=30 (number of profiles along the crossrange direction), Ntheta $=160$ (number of radials), theta [40 40] (first and last radial angle), Nalpha $=160$ (number of
Gaussian beams), alpha [-40 40] (first and last angle for beam fan), $S T E P=10 \mathrm{~m}$ (beam step size), NSTEPS $=6000$ (number of steps), EPMULT=0.3 (Epsilon multipler for beam initial conditions) are considered. Spatial resolutions should be used in range $(\Delta x)$ and water depth $(\Delta z)$.

\section{RESULTS}

\section{A. AIS}

Figure 2 (blue points) shows all dynamic messages from Class A AIS transmitters at the Balearic Sea received during September 2019. This is, an accumulative graphic representation of all the vessels present during that month in the Balearic Sea, which does not include smaller and recreational vessels hosting a Class B AIS transmitter

The regular line covering the route from Alcudia (North of Mallorca Island) to Barcelona is represented in orange colour in Figure 2. It is a daily line operated by a single company with Ro-Ro and Ro-Pax vessels, with Saturday stops at the Port of Barcelona for maintenance operations. The trip is around 6 hours long and departs from the Port of Alcudia at 1:00 pm with the trip back leaving the Port of Barcelona around 10:00 $\mathrm{pm}$. According to AIS data, the line did not operate as expected in September 10th and 11th due to severe storm conditions.

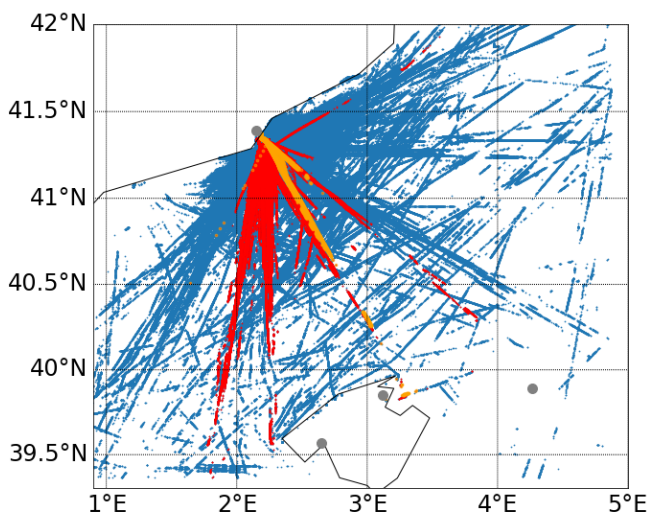

Fig. 2. Dynamic messages from class A ships received during September 2019 (blue) and Ferry lines covering the route from Barcelona to Balearic Islands (red and orange), with orange points covering the route from Alcudia to Barcelona (Mallorca). Gray points represent the cities of Barcelona, Palma, Alcudia and Maó.

\section{B. Underwater acoustic modeling}

Based on the AIS data analysis, a representative ferry route between $39.88^{\circ} \mathrm{N}, 3.37^{\circ} \mathrm{W}$ (Alcudia) and $41.35^{\circ} \mathrm{N}, 2.19^{\circ} \mathrm{W}$ (Barcelona) is considered. Simulations are performed for two different sound speed models i) 2nd September 2019 and ii) 2nd February 2020, both at at 11:30 am. Figure 3 shows the bathymetric and sound speed models between Alcudia and Barcelona. 

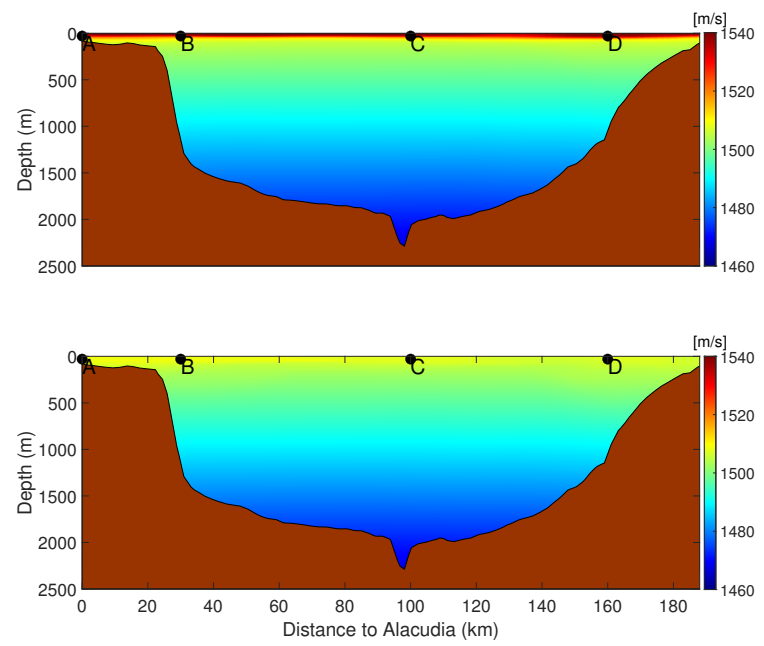

Fig. 3. Bathymetric and sound speed models between Alcudia and Barcelona for 2nd September 2019 at 11:30 am (top) and 2nd February 2020 at 11:30 am (bottom).

The first $22 \mathrm{~km}$ of the representative route are located in the northern shelf of the Balearic Islands [28] and the water depth ranges between approximately 90 and $140 \mathrm{~m}$ (at the shelf break). From approximately 22 to $40 \mathrm{~km}$, the route crosses the continental slope and water depth abruptly increases to 1500 $\mathrm{m}$. From 40 to $150 \mathrm{~km}$, ferries are in deep waters with water depth varying between 1500 and $2300 \mathrm{~m}$. The last $40 \mathrm{~km}$ of the ferry route are over the Catalan continental slope (1500 to $26 \mathrm{~m}$ water depth).

Figure 4 shows Transmission Loss (TL) over $4 \mathrm{~km}$ range at 10 and $60 \mathrm{~m}$ water depth for a ferry located at 0 (A), 30 (B), 100 (C) and 160 (D) km away from Alcudia (see Figure 3 for point locations). The source depth simulations is placed $1 \mathrm{~m}$ below the free surface. TL in Figure 4 is presented both for September 2019 and February 2020 sound speed models. For sound source located at point A (on the Balearic Continental Shelf), less TL is observed than for the other 3 points. Moreover, for source point A, TL levels are similar at 10 and $60 \mathrm{~m}$ depth. On the other hand, for source points B, C, and D significant differences are observed in the first $0.5 \mathrm{~km}$ at 10 and $60 \mathrm{~m}$ depth. Overall, at $60 \mathrm{~m}$ depth more variability is observed than at $10 \mathrm{~m}$ depth due to the sound speed model considered.

\section{DISCUSSION}

The central part of the route is more costly in terms of computational resources needed because of its deeper bathymetry. This fact significantly increases the computational cost in Kraken because more modes exist and should be computed in Kraken and taken into account running Field.

Geoacoustics properties of sediments can be predicted based on measured values of one or more sediment physical properties [29]. In this regard, regressions based on laboratory and in situ measurements can give bottom wave speed or
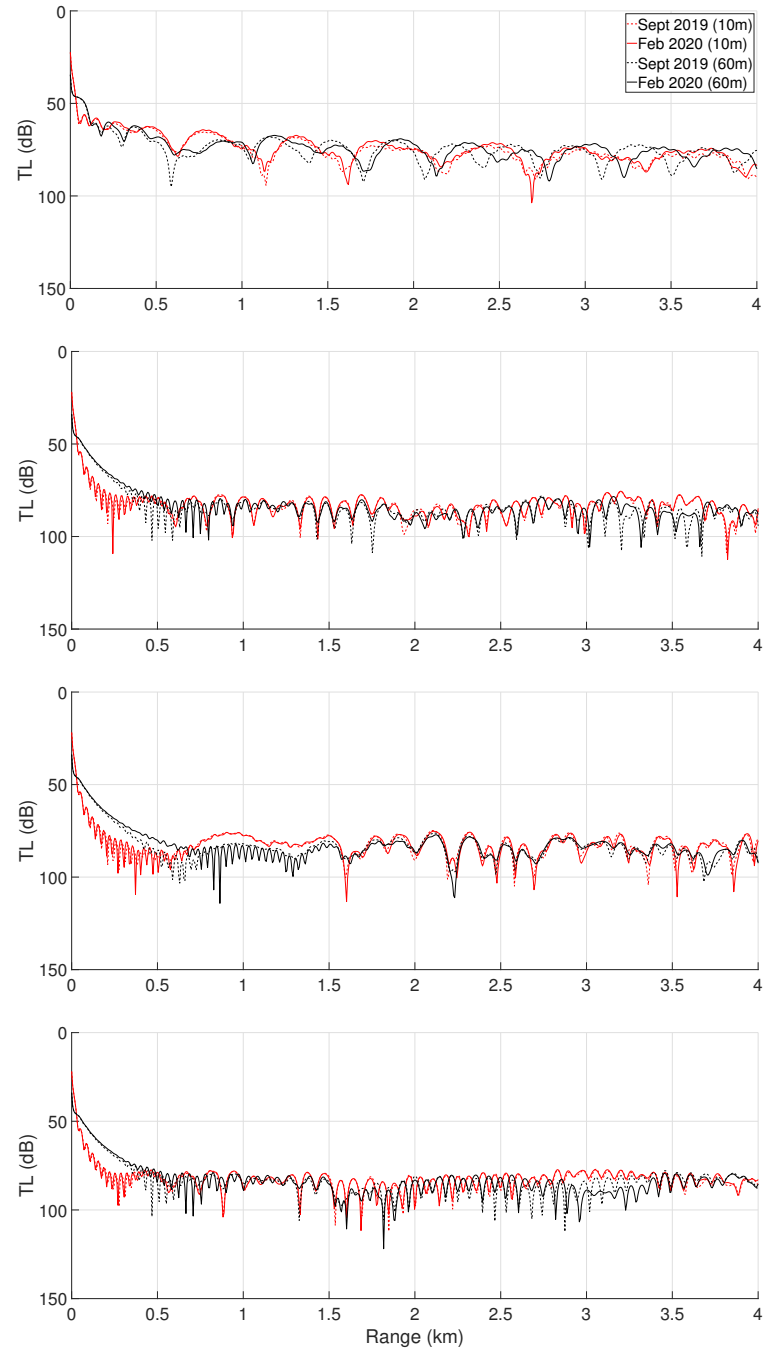

Fig. 4. Transmission Loss (TL) over range at $10 \mathrm{~m}$ (red line) and $60 \mathrm{~m}$ (black line) water depth for a $50 \mathrm{~Hz}$ ship noise source. Top to bottom plots correspond to ship location at A,B,C, and D (see Figure 3), respectively. TL is calculated considering February 2020 (Dash-line) and September 2019 (solid line) sound speed models.

attenuation based on sediment physical properties such as grain size or porosity. Likewise, geoacoustic properties based on sediment physical properties can also be obtained from tabulated handbook values [30], [31].

\section{CONCLusions}

We presented a novel methodology to model the underwater noise induced by ship traffic in the Balearic Sea. AIS data is used to estimate the trip line between Alcudia and Barcelona and obtain the most significant cruising parameters.

\section{ACKNOWLEDGMENT}

The first author thanks FCT/MCTES for the financial support to CESAM (UID/AMB/50017/2019), through national funds. AM and JF thank the Serra Húnter program. 
TABLE I

TABLE TYPE STYLES

\begin{tabular}{|l|c|c|c|}
\hline Table & \multicolumn{3}{|c|}{ Table Column Head } \\
\cline { 2 - 4 } Head & Table column subhead & Subhead & Subhead \\
\hline copy & More table copy ${ }^{\mathrm{a}}$ & & \\
\hline
\end{tabular}

\section{REFERENCES}

[1] S. B. L., "Marine mammal noise exposure criteria: Initial scientific recommendations," Aquat. Mamm., vol. 33, p. 411, 2007.

[2] G. D. Hastie, D. J. Russell, B. McConnell, S. Moss, D. Thompson, and V. M. Janik, "Sound exposure in harbour seals during the installation of an offshore wind farm: predictions of auditory damage," Journal of Applied Ecology, vol. 52, no. 3, pp. 631-640, 2015. [Online]. Available: https://besjournals.onlinelibrary.wiley.com/doi/abs/10.1111/13652664.12403

[3] G. Shannon, M. F. McKenna, L. M. Angeloni, K. R. Crooks, K. M. Fristrup, E. Brown, K. A. Warner, M. D. Nelson, C. White, J. Briggs, S. McFarland, and G. Wittemyer, "A synthesis of two decades of research documenting the effects of noise on wildlife," Biological Reviews, vol. 91, no. 4, pp. 982-1005, 2016. [Online]. Available: https://onlinelibrary.wiley.com/doi/abs/10.1111/brv.12207

[4] R. D. McCauley, R. D. Day, K. M. Swadling, Q. P. Fitzgibbon, R. A. Watson, and J. M. Semmens, "Widely used marine seismic survey air gun operations negatively impact zooplankton," Nature ecology \& evolution, vol. 1, no. 7, p. 0195, 2017.

[5] J. Fewtrell and R. McCauley, "Impact of air gun noise on the behaviour of marine fish and squid," Marine Pollution Bulletin, vol. 64, no. 5, pp. 984 - 993, 2012. [Online]. Available: http://www.sciencedirect.com/science/article/pii/S0025326X12000872

[6] R. Williams, C. Erbe, E. Ashe, and C. W. Clark, "Quiet (er) marine protected areas," Marine pollution bulletin, vol. 100, no. 1, pp. 154161, 2015.

[7] D. René, T. Mark, V. D. G. Sandra, A. Michael, A. Mathias, A. É. scientifique Michel, B. Karsten, C. Manuel, C. Donal, D. John, F. Thomas, L. Russell, P. Jukka, R. Paula, R. Stephen, S. Peter, S. Gerry, T. Frank, W. Stefanie, W. Dietrich, and Y. John, "Monitoring guidance for underwater noise in european seas," Publ. Off. Eur. Union, Luxemb, Tech. Rep. JRC Sci. Policy Rep. EUR 26557 EN, 2014.

[8] D. Ross and W. Kuperman, "Mechanics of underwater noise," 1989.

[9] "A simple model for the underwater noise source level of ships," Journal of Ship Production and Design, vol. 30, no. 1, 2014.

[10] F. Traverso, T. Gaggero, G. Tani, E. Rizzuto, A. Trucco, and M. Viviani, "Parametric analysis of ship noise spectra," IEEE Journal of Oceanic Engineering, vol. 42, no. 2, pp. 424-438, 2016.

[11] E. Jansen and C. de Jong, "Experimental assessment of underwater acoustic source levels of different ship types," IEEE Journal of Oceanic Engineering, vol. 42, no. 2, pp. 439-448, April 2017.

[12] Z. Peng, B. Wang, and J. Fan, "Assessment on source levels of merchant ships observed in the east china sea," Ocean Engineering, vol. 156, pp. 179 - 190, 2018. [Online]. Available: http://www.sciencedirect.com/science/article/pii/S0029801818301847

[13] S. T. Neenan, P. R. White, T. G. Leighton, and P. J. Shaw, "Modeling vessel noise emissions through the accumulation and propagation of automatic identification system data," in Proceedings of Meetings on Acoustics 4ENAL, vol. 27, no. 1. Acoustical Society of America, 2016, p. 070017.

[14] J.-P. Jalkanen, L. Johansson, M. Liefvendahl, R. Bensow, P. Sigray, M. Östberg, I. Karasalo, M. Andersson, H. Peltonen, and J. Pajala, "Modelling of ships as a source of underwater noise," Ocean Science, vol. 14, no. 6, pp. 1373-1383, 2018. [Online]. Available: https://www.ocean-sci.net/14/1373/2018/

[15] L. E. Trigg, F. Chen, G. I. Shapiro, S. N. Ingram, and C. B. Embling, "An adaptive grid to improve the efficiency and accuracy of modelling underwater noise from shipping," Marine Pollution Bulletin, vol. 131, pp. 589 - 601, 2018. [Online]. Available: http://www.sciencedirect.com/science/article/pii/S0025326X1830256X

[16] J. Potter and A. Warn-Varnas, Ocean variability \& acoustic propagation. Springer Science \& Business Media, 2012.
[17] T. C. A. Oliveira and Y.-T. Lin, "Three-dimensional global scale underwater sound modeling: The t-phase wave propagation of a southern mid-atlantic ridge earthquake," The Journal of the Acoustical Society of America, vol. 146, no. 3, pp. 2124-2135, 2019. [Online]. Available: https://doi.org/10.1121/1.5126010

[18] M. B. Porter, "Beam tracing for two- and three-dimensional problems in ocean acoustics," The Journal of the Acoustical Society of America, vol. 146, no. 3, pp. 2016-2029, 2019. [Online]. Available: https://doi.org/10.1121/1.5125262

[19] A. Alessandrini, D. Guizzardi, G. Janssens-Maenhout, E. Pisoni, M. Trombetti, and M. Vespe, "Estimation of shipping emissions using vessel long range identification and tracking data," Journal of Maps, vol. 13, no. 2, pp. 946-954, 2017. [Online]. Available: https://doi.org/10.1080/17445647.2017.1411842

[20] M. L. Fernndez de Puelles and J. C. Molinero, "North atlantic climate control on plankton variability in the balearic sea, western mediterranean," Geophysical Research Letters, vol. 34, no. 4, $2007 . \quad$ [Online]. Available: https://agupubs.onlinelibrary.wiley.com/doi/abs/10.1029/2006GL028354

[21] J. Navarro, M. Coll, M. Louzao, I. Palomera, A. Delgado, and M. G. Forero, "Comparison of ecosystem modelling and isotopic approach as ecological tools to investigate food webs in the nw mediterranean sea," Journal of Experimental Marine Biology and Ecology, vol. 401, no. 1-2, pp. 97-104, 2011.

[22] E. Clementi, J. Pistoia, D. Delrosso, G. Mattia, C. Fratianni, A. Storto, S. A. Ciliberti, B. Lemieux-Dudon, E. Fenu, S. Simoncelli et al., "A $1 / 24$ degree resolution mediterranean analysis and forecast modeling system for the copernicus marine environment monitoring service," in Eight EuroGOOS International Conference, 2017.

[23] G. Madec, "Nemo ocean engine v3. 4, note du pole de modélisation," 2012.

[24] W. Kuperman, M. B. Porter, J. S. Perkins, and R. B. Evans, "Rapid computation of acoustic fields in three-dimensional ocean environments," The Journal of the Acoustical Society of America, vol. 89, no. 1, pp. 125-133, 1991.

[25] M. Porter and E. L. Reiss, "A numerical method for oceanacoustic normal modes," The Journal of the Acoustical Society of America, vol. 76, no. 1, pp. 244-252, 1984. [Online]. Available: https://doi.org/10.1121/1.391101

[26] M. B. Porter, "The kraken normal mode program," Naval Research Lab Washington DC, Tech. Rep., 1992.

[27] K. V. Mackenzie, "Nineterm equation for sound speed in the oceans," The Journal of the Acoustical Society of America, vol. 70, no. 3, pp. 807-812, 1981. [Online]. Available: https://doi.org/10.1121/1.386920

[28] J. Acosta, M. Canals, J. Lpez-Martnez, A. Muoz, P. Herranz, R. Urgeles, C. Palomo, and J. L. Casamor, "The balearic promontory geomorphology (western mediterranean): morphostructure and active processes," Geomorphology, vol. 49, no. 3, pp. 177 - 204, 2003. [Online]. Available: http://www.sciencedirect.com/science/article/pii/S0169555X0200168X

[29] D. Jackson and M. Richardson, High-frequency seafloor acoustics. Springer Science \& Business Media, 2007.

[30] E. L. Hamilton, "Geoacoustic modeling of the sea floor," The Journal of the Acoustical Society of America, vol. 68, no. 5, pp. 1313-1340, 1980.

[31] F. B. Jensen, W. A. Kuperman, M. B. Porter, and H. Schmidt, Computational ocean acoustics. Springer Science \& Business Media, 2011. 